\title{
Spectral radiance of blue light filters on ophthalmic lenses
}

\section{Radiancia espectral de lentes oftálmicas con filtros de luz azul}

\author{
Cristina Fernández, Marc Argilés, Elisabet Pérez-Cabrés* Genís Cardona \\ 1. School of Optics and Optometry, Universitat Politècnica de Catalunya, \\ Vionista Vellsolà 37, 08222 Terrassa (Barcelona) \\ (*) E-mail: elisabet.perez@upc.edu \\ S: SEDOPTICA member \\ Received: 30/12/2016 Accepted: 29/05/2017 \\ DOI: $10.7149 /$ OPA.50.2.49072
}

\begin{abstract}
:
As a result of the recent improvement in light-emitting diode (LED) technology, the displays of the vast majority of electronic devices are now illuminated by LEDs. There are several advantages of this type of light source over its predecessors; however, recent research is giving support to the fact that prolonged exposition to the white LEDs emission in the blue spectrum may have a negative impact on visual health, as well as, on biological rhythms (circadian rhythms). As a consequence, ophthalmic lens manufacturers have recently introduced in the market innovative lenses that incorporate blue light filters, especially designed for electronic device users. In this work, the performance of different blue light filters present on commercially available ophthalmic lenses was tested and compared. Lenses were placed in front of a LED-based backlight tablet, in a similar way a common user would be reading a text on the electronic device. The absorption characteristics of the various samples from four different ophthalmic lens manufacturers were measured. Analysis of the different samples from the same manufacturer was conducted and blue light filters from different manufacturers were compared.
\end{abstract}

Key words: Blue light filters, ophthalmic lenses, LED backlight screens, electronic devices, circadian rhythm

\section{RESUMEN:}

Como resultado de las mejoras en la tecnología LED (del inglés, light-emitting diode), las pantallas de la mayoría de dispositivos electrónicos actuales están iluminadas por LEDs. Muchas son las ventajas de esta fuente de luz sobre las fuentes predecesoras; sin embargo, algunas investigaciones recientes han puesto de manifiesto el hecho que la exposición prolongada a la emisión en la zona azul del espectro de los LEDs blancos puede tener un efecto negativo en la salud visual y en los ritmos biológicos (ritmos circadianos). Como consecuencia de ello, los fabricantes de lentes oftálmicas han introducido recientemente en el mercado lentes innovadoras que incorporan filtros de luz azul, especialmente diseñadas para los usuarios de dispositivos electrónicos. En este trabajo, se evaluaron y compararon diferentes filtros de luz azul en lentes oftálmicas comerciales. Se disponían las lentes frente a una tableta retro-iluminada con LEDs, de manera similar a como un usuario se situaría delante del dispositivo electrónico para leer un texto. Se analizó la capacidad de absorción de varias muestras de un mismo fabricante, y se comparó el resultado entre filtros azules de distintas marcas comerciales.

Palabras clave: Filtros de luz azul, lentes oftálmicas, pantallas retro-iluminadas por LED, dispositivos electrónicos, ritmo circadiano

\section{REFERENCES AND LINKS / REFERENCIAS Y ENLACES}

[1] Z. Yan, L. Hu, H. Chen, F. Lu, "Computer Vision Syndrome: A widely spreading but largely unknown epidemic among computer users," Computers in Human Behaviour, 24(5), 2026-2042 (2008). https://doi.org/10.1016/j.chb.2007.09.004 
[2] M. Rosenfield, "Computer vision syndrome: a review of ocular causes and potential treatments," Ophthalmic Physiol. Opt., 31(5), 502-515 (2011). https://doi.org/10.1111/j.1475-1313.2011.00834.x

[3] C. Chu, M. Rosenfield, J. K. Portello, J. Benzoni, J. D. Collier, "A comparison of symptoms after viewing text on a computer screen and hardcopy," Ophthalmic Physiol. Opt., 31 (1), 29-32 (2011). https://doi.org/10.1111/j.1475-1313.2010.00802.x

[4] R. Courtin, B. Pereira, G. Naughton, A. Chamoux, F. Chiambaretta, C. Lanhers, F. Dutheil, "Prevalence if dry eye disease in visual terminal workers: a systematic review and meta-analysis," BMJ Open, 6, e009675 (2016).

https://doi.org/10.1136/bmjopen-2015-009675

[5] M. Argilés, G. Cardona, E. Pérez-Cabré, M. Rodríguez, "Blink rate and incomplete blinks in six different controlled hard-copy and electronic displays," Invest. Ophthalmol. Vis. Sci., 56 (11), 6679-6685 (2015). https://doi.org/10.1167/iovs.15-16967

[6] F. Behar-Cohen, C. Martinsons, F. Viénot, G. Zissis, A. Barlier-Salsi, J. P. Cesarini, O. Enouf, M. García, S. Picaud, D. Attia, "Light-emitting diodes (LED) for domestic lighting: Any risks for the eye?," Prog. Retin. Eye Res., 30 (4), 239-257 (2011). https://doi.org/10.1016/j.preteyeres.2011.04.002

[7] J. F. Duffy, C. A. Czeisler, "Effect of light on human circadian physiology," Sleep Med. Clin., 4 (2), 165177 (2009). https://doi.org/10.1016/j.jsmc.2009.01.004

[8] G. C. Brainard, J. P. Hanifin, J. M. Greeson, B. Byre, G. Glickman, E. Gerner, M. Rollang, "Action spectrum for melatonin regulation in humans: evidence for a novel circadion photoreceptor," J. Neurosci., 21 (16), 6405-6412 (2001).

[9] B. Wood, M. S. Rea, B. Plitnick, M. Figueiro, "Light level and duration of exposure determine the impact of self-luminous tablets on melatonin suppression," Appl. Ergon., 44 (2), 237-240 (2013). https://doi.org/10.1016/j.apergo.2012.07.008

[10] M. Figueiro, B. Plitnick, B. Wood, M. Rea, "The impact of light computer monitor on melatonin levels in college students," Neuro Endocrinol Lett., 32 (2), 58-63 (2011).

[11] S. L. Chellappa, R. Steiner, P. Oelhafen, D. Lang, T. Götz, J. Krebs, C. Cajochen, "Acute exposure to evening blue-enriched light impacts on human sleep," J. Sleep. Res., 22 (5), 573-580 (2013).

https://doi.org/10.1111/jsr.12050

[12] C. Cajochen, S. Frey, D. Anders, J. Spati, M. Bues, A. Pross, R. Mager, A. Wirz-Justice, O. Stefani, "Evening exposure to a light-emitting diodes (LED)-backlit computer screen affects circadian physiology and cognitive performance," J. Appl. Physiol., 110, 1432-1438 (2011).

https://doi.org/10.1152/japplphysiol.00165.2011

[13] A. Chang, D. Aeschbach, J. F. Duffy, C. A. Czeisler, "Evening use of light-emitting eReaders negatively affects sleep, circadian timing and next-morning alertness," PNAS, 112 (4), 1232-1237 (2015). https://doi.org/10.1073/pnas.1418490112

[14] Reticare: http://www.reticare.com. Date of access December 23rd 2016.

[15] J. Escofet, S. Bará, "Reducing the circadian input from self-luminous devices using hardware filters and software applications," Lighting Res. Technology, 49, 481-496 (2017). https://doi.org/10.1177/1477153515621946

[16] S. van der Lely, S. Frey, C. garbazza, A. Wirz-Justice, O. G. Jenni, R. Steiner, S. Wolf, C. Cajochen, V. Bromundt, C. Schmidt, "Blue blocker glasses as a countermeasure for alerting effects of evening lightemitting diode screen exposure in male teenagers," J. of Adolescent Health, 56, 113-119 (2015). https://doi.org/10.1016/j.jadohealth.2014.08.002

\section{Introduction}

In modern society the use of electronic digital devices is rapidly increasing, with computers, smartphones, tablets and televisions being ubiquitous. As a result, all age groups (children, youth and adults) report increasingly demanding visual tasks. In addition, particular research efforts are being directed to evaluate the relation between the use of electronic displays and some visual problems [1-3]. In particular, in 2008 the American Optometric Association defined the Computer Vision Syndrome (CVS) as the combination of ocular and vision problems initially associated with the use of computers [1-3], a definition that may nowadays be extrapolated to the use of any other type of modern electronic display. One of the most 
prevalent problems associated with CVS is dry eye [4]. Researchers have reported that ocular discomfort, specifically dry eye symptoms, may be associated with an increase of incomplete blinks (that is, the eye is not completely closed in the downward process of a blink) when electronic displays are used [5].

Overall, one of the main components of electronic devices is a backlight screen consisting of a liquid crystal display (LCD) layer and a light source, which is set behind the screen. This illumination system allows the use of these devices in poorly lit environments and, in general, improves and facilitates visualization of data shown in the screen. Until recently, the most commonly used backlight system was based on cold cathode fluorescent light (CCFL). As a consequence of the recent improvement in light-emitting diode (LED) technology, the screens of the vast majority of electronic devices are now illuminated by white light LEDs. Two LED configurations are available: those emitting white light from a phosphorous coating and those compounding white light by combining red, blue and green (RGB) LEDs. The advantages of the LED technology over previous illumination systems are numerous, such as affording a wider variety of colours, higher contrast and resolution, and thinner screens, among others. Nevertheless, some disadvantages have also been described, which are currently still under study. For example, prolonged exposition to the white LEDs main emission in the blue area of the visible spectrum may have a negative impact on visual health, as well as, on biological rhythms (circadian rhythms) [6,7]. Some of the negative effects of this radiation may originate in the coincidence of the white light LED emission peak (at approximately $450 \mathrm{~nm}$ ) with the wavelength of maximum absorption of the melanopsin pigment of the retina (around $460 \mathrm{~nm}$ ), which regulates the cycle of sleeping and waking in human biological rhythms (Fig. 1).

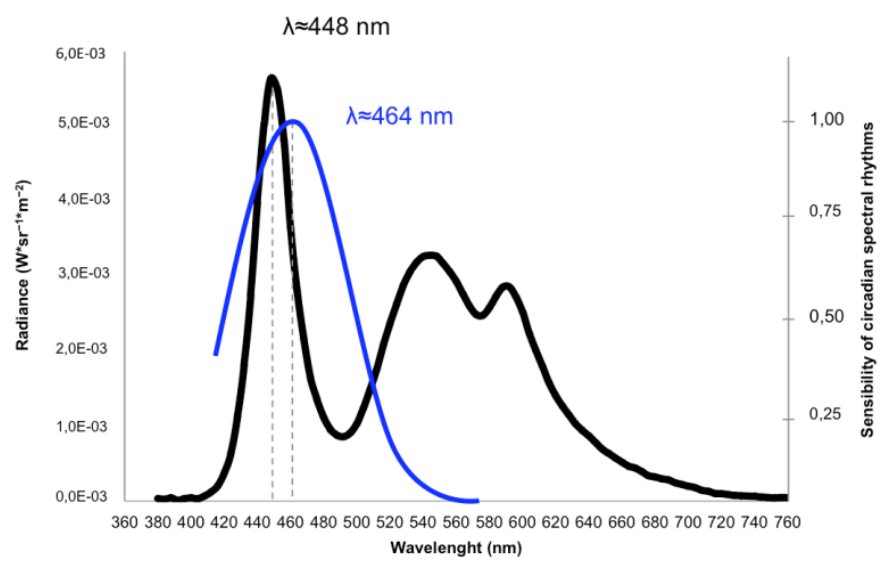

Fig.1. Spectral radiance of a LED backlight screen (in black) and normalized spectral absorption values of the melanopsin pigment (in blue)

It has been observed that, under natural conditions, the circadian cycle oscillates according to light exposure (specifically, light from the blue or short wavelength spectral region). At night, in dim light or darkness, melatonin (or sleep hormone) secretion by the pineal gland is initiated, allowing the human body to become ready to sleep and rest. On the contrary, during the day, melatonin secretion is stopped under the exposure to sunlight, thus promoting a state of alertness and wakefulness. Nevertheless, this biorhythm cannot differentiate exposure to a natural light source from that of an artificial light. Thereby, some studies have documented a disruption of circadian rhythms with the use of electronic displays at night [8,9] and an inhibition of melatonin production by the effect of the blue light emission of LED displays [10-13].

In order to reduce the level of the emitted blue light reaching the eyes of electronic display users, different approaches have recently been implemented. For instance, a set of filters with different attenuation levels is commercially available [14]. These filters are designed to be attached to the displays, so that they partially block the blue light emission of the device. Another possibility is to install and activate an application for computers, smartphones or tablets. This software will automatically control the emission of the display according to the time of the day the user is employing the device, moving towards warmer colours towards the end of the day. Both, hardware filters and software applications were recently compared [15]. A recent work has investigated the use or orange-tinted blue blocker therapeutic lenses to reduce the effects of LED illuminated screens on evening users of these devices [16]. Finally, several ophthalmic lens manufacturers have introduced in the market innovative ophthalmic lenses incorporating blue light filters. These lenses 
are specifically recommended for ordinary users of electronic devices, thus allowing prolonged exposure to the screen radiation, or for night-time users.

In this work, the performance of different blue light filters incorporated in commercially available ophthalmic lenses was tested and compared. In section 2, a detailed description of the materials used for the experiments as well as the tested samples is provided. Section 3 focuses on the analysis of the obtained results, comparing the absorption capacity of various samples of the same manufacturer and also comparing various samples from four different ophthalmic lens manufacturers. Finally, conclusions are summarized in Section 4.

\section{Material and method}

\section{2.a. Experimental setup}

The current study used an iPad mini ME280TY/A tablet from Apple as an example of a self-luminous screen with LED technology. The illuminating system consists of an array of RGB LEDs as shown in the microscopic view of Fig. 2(a). The area of this tablet is $20 \times 13.47 \mathrm{~cm}$ and was used as the illuminating light source for all the experimental measurements of the ophthalmic lenses under study. The tablet displayed a uniform white picture filling the whole screen in its maximum radiance and was always plugged to the external power supply network to ensure the maximum RGB LED emission. Under these conditions, the initial emission spectrum of the tablet was taken as a reference to lately compute the spectral transmission of the ophthalmic lenses. The radiometric measurements in this study were obtained with the spectroradiometer "Photo Research PR-715", a device that allows for the analysis of the visible spectrum (380-780nm) in 4nm steps (Figure 3). Figure 2(b) shows the experimentally measured spectral radiance of the tablet displaying a white uniform image in its maximum radiance.

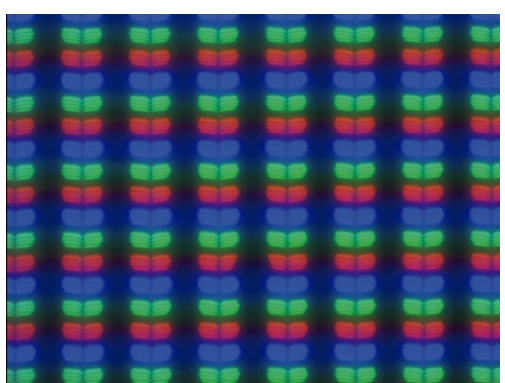

(a)

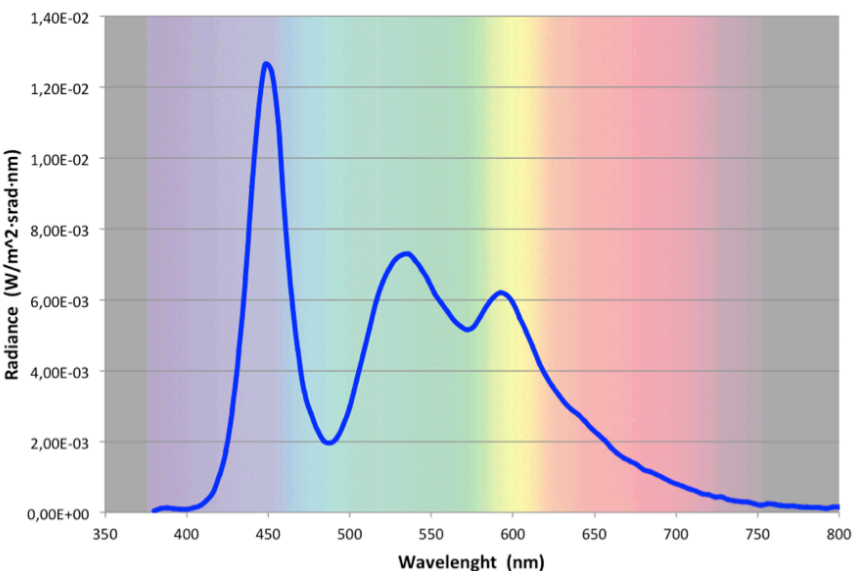

(b)

Fig. 2 (a) Microscopic view of the RGB LED array of the iPad mini ME280TY/A tablet. (b) Spectral emission of the same device.

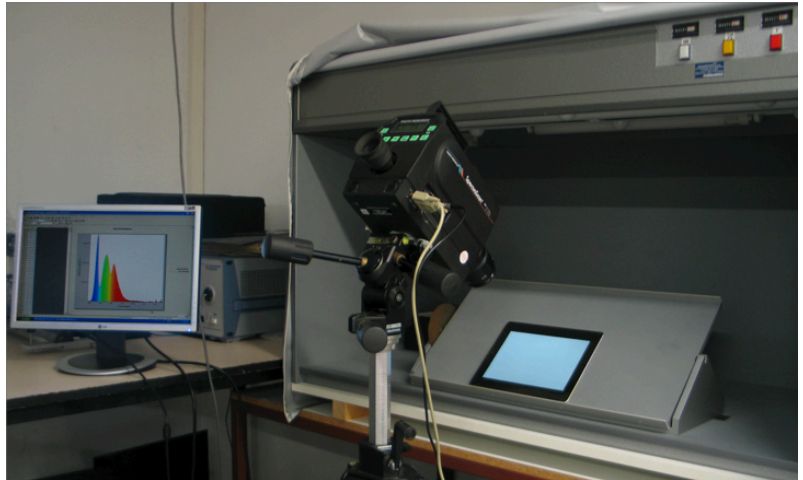

Fig. 3 Spectroradiometer (Photo Research PR-715) used in the experiments.

The analysed samples of ophthalmic lenses were sequentially placed in front of the spectroradiometer, centred to the optical axis. The orientation effect of the lenses with reference to the display was first considered. Preliminary measurements evidenced no variation in the readings of the spectroradiometer 
irrespective of the actual orientation of the lenses (concave or convex surface facing the display). Therefore, subsequent measurements were conducted with samples placed with the convex curvature facing the tablet, which is the same orientation a user would employ the lenses when reading a text on the electronic device. The spectral radiance for each lens was recorded and compared to the spectral emission of the tablet screen without the lens. Therefore, any variation in the measured spectral radiance would account for the absorption characteristics of the analysed ophthalmic lens. The ratio between the spectral radiance of the tablet with and without the lens provides the percentage of filter transmission for each analysed wavelength. Figure 3 shows the experimental setup, including the spectroradiometer used to obtain the spectral information of the study samples. All measurements were taken under the same environmental conditions and during the same session.

\section{2.b. Analysed ophthalmic samples}

Nowadays, several manufacturers incorporate blue filters in commercially available ophthalmic lenses. This study evaluated samples from four different manufacturers: Prats, Indo, Hoya and Essilor. In all but one case, lenses with blue filter were compared with lenses incorporating only the common anti-reflective (AR) coating, with all the other parameters remaining constant (lens material, surface geometry, refractive power, etc.).

Table 1 shows the number of evaluated samples as grouped by manufacturer. There was only one sample from Hoya, corresponding to the blue filter, that is, the lens with AR coating was not available in time for the study. However, the authors considered interesting to include this sample in the analysis to allow for comparison with the other lenses incorporating blue radiation filters. In contrast, there were 4 different samples from Prats: one with the AR coating, one with the blue filter for electronic device users (CSR) and two more samples defined as therapeutic lenses, with filters CSRa and CSRb.

\begin{tabular}{c|c|c|c} 
Table 1. Number of samples for each of the analysed lenses with information on the intensity of the bl \\
\hline Brand & $\begin{array}{c}\text { Total } \\
\text { number of } \\
\text { samples }\end{array}$ & $\begin{array}{c}\text { Samples with only } \\
\text { anti-reflective (AR) } \\
\text { coating }\end{array}$ & $\begin{array}{c}\text { Samples with blue filter } \\
\text { (intensity of filter) }\end{array}$ \\
\hline \hline Prats ${ }^{\circledR}$ & 4 & $1-\mathrm{AR}$ & 3 - CSR; CSRa; CSRb \\
Indo $^{\circledR}$ & 2 & $1-\mathrm{AR}$ & 1 - Energy \\
Hoya $^{\circledR}$ & 1 & 0 & 1 - Blue Control \\
Essilor $^{\circledR}$ & 2 & 1 - AR & 1 - Crizal Prevencia \\
\hline \hline
\end{tabular}

Figure 4 shows the analysed ophthalmic lens samples incorporating blue filter. A certain yellowish colour may be observed from some of the samples since lenses have a selective absorption in the blue component of the visible spectrum.

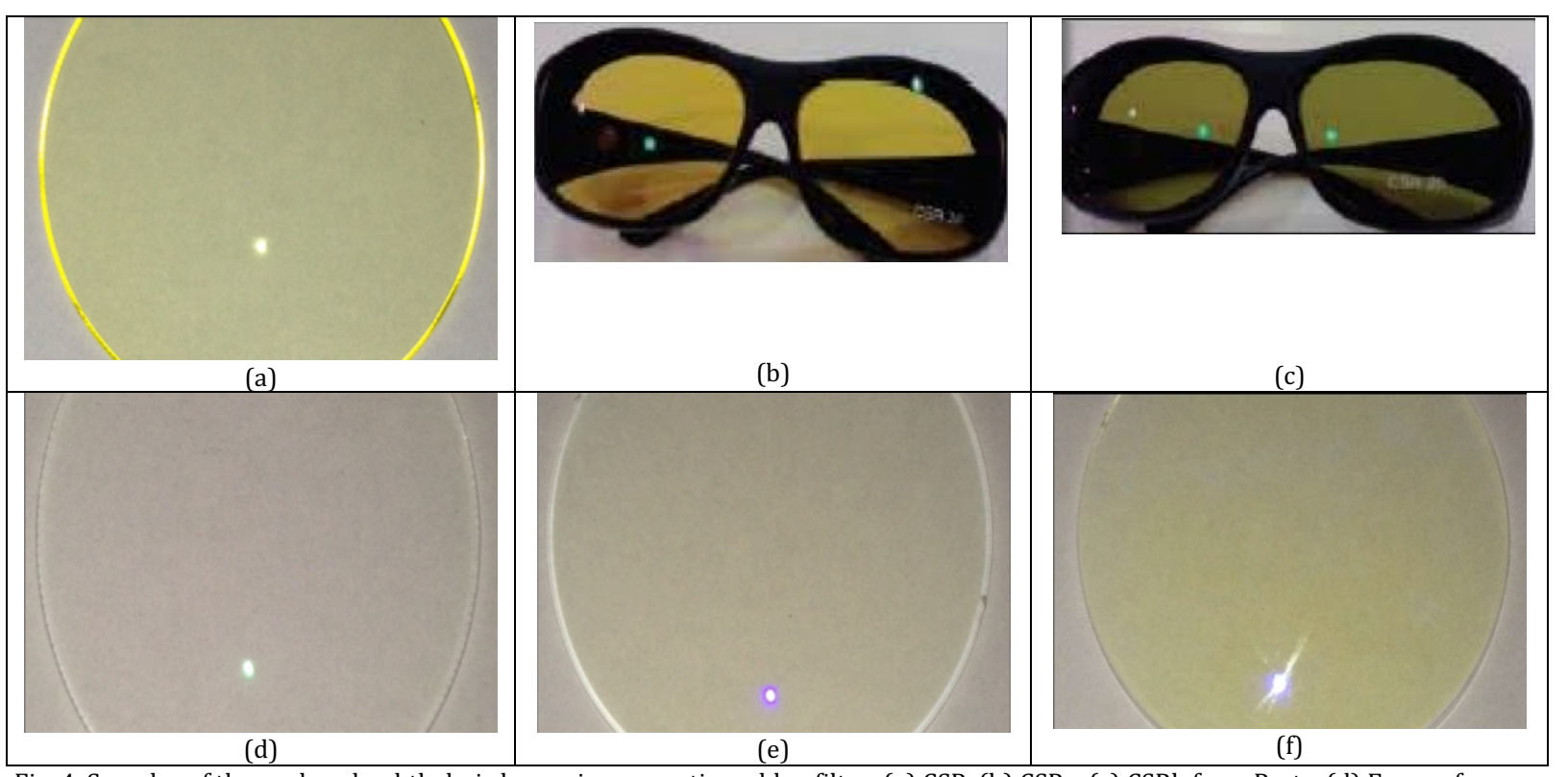

Fig. 4. Samples of the analysed ophthalmic lenses incorporating a blue filter: (a) CSR, (b) CSRa, (c) CSRb from Prats; (d) Energy from Indo; (e) Blue Control from Hoya; (f) Crizal Prevencia from Essilor. 


\section{Results}

In this section, the spectral radiances and transmittances of the samples belonging to the same manufacturer are shown and compared. In all cases, the tablet spectral radiance is also plotted for comparison purposes.

Figure 5 shows the spectral radiances and transmittances corresponding to the Prats ophthalmic lenses. It may be observed that the AR coating rarely absorbed light from any wavelength of the visible spectrum, with a radiance curve clearly overlapping the emission curve of the iPad tablet. On the contrary, the three CSR filter samples each modified in a different degree the evaluated spectrum. The CSR sample designed for electronic device users specifically absorbed the blue region of the spectrum, where the RGB LEDs emission has the highest intensity. The CSRa and CSRb samples, however, modified the whole of the visible spectrum, manifesting a significant absorption in all chromatic components, with the strongest effect in the short wavelengths. Note that these therapeutic lenses are commonly recommended to avoid dazzle in those patients with light sensitive retinas.
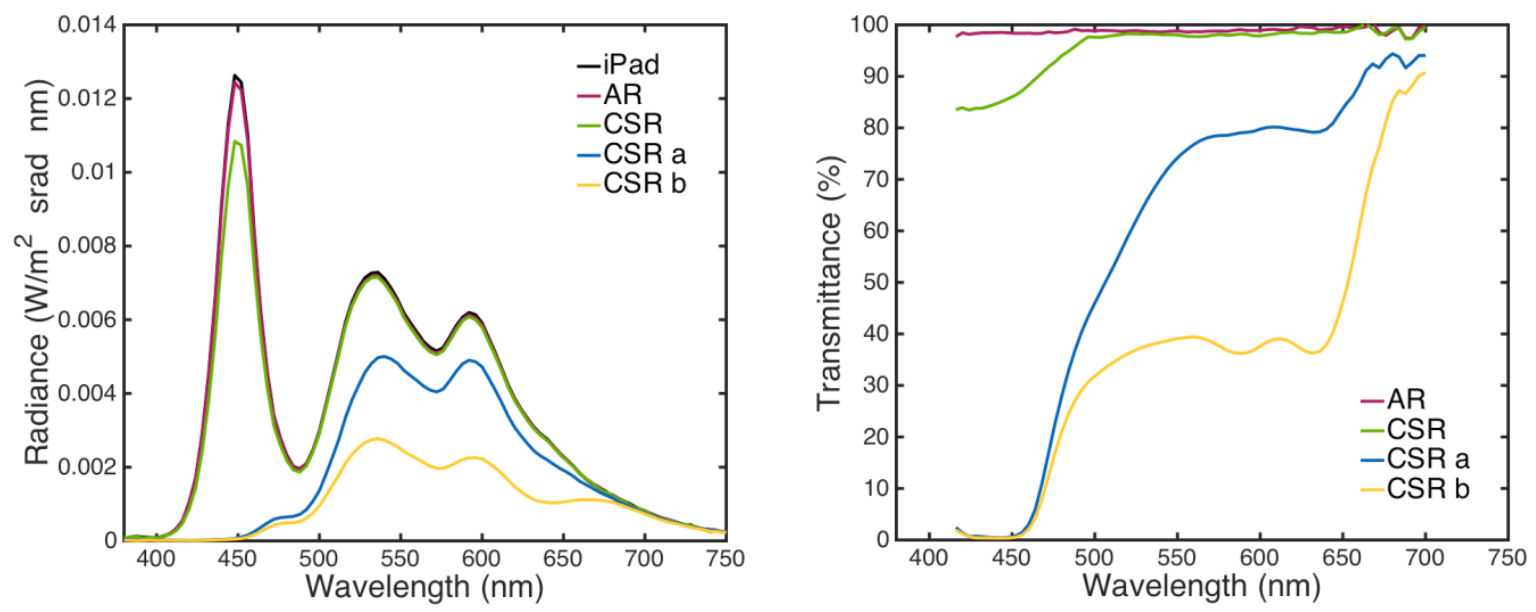

Fig. 5. Spectral radiances and transmittances obtained from the set of ophthalmic lenses from Prats. The curve of the tablet screen emission is shown for comparison.

Figure 6 depicts the results for the Indo ophthalmic lenses. Hardly noticeable differences in the spectral radiances measured from the tablet screen, the AR coating and the energy filter were evidenced, although a tiny reduction of the radiance in the blue region of the spectrum may be appreciated with the blue light filter. This effect can be clearly observed in the transmittance plot on the right of Figure 6.
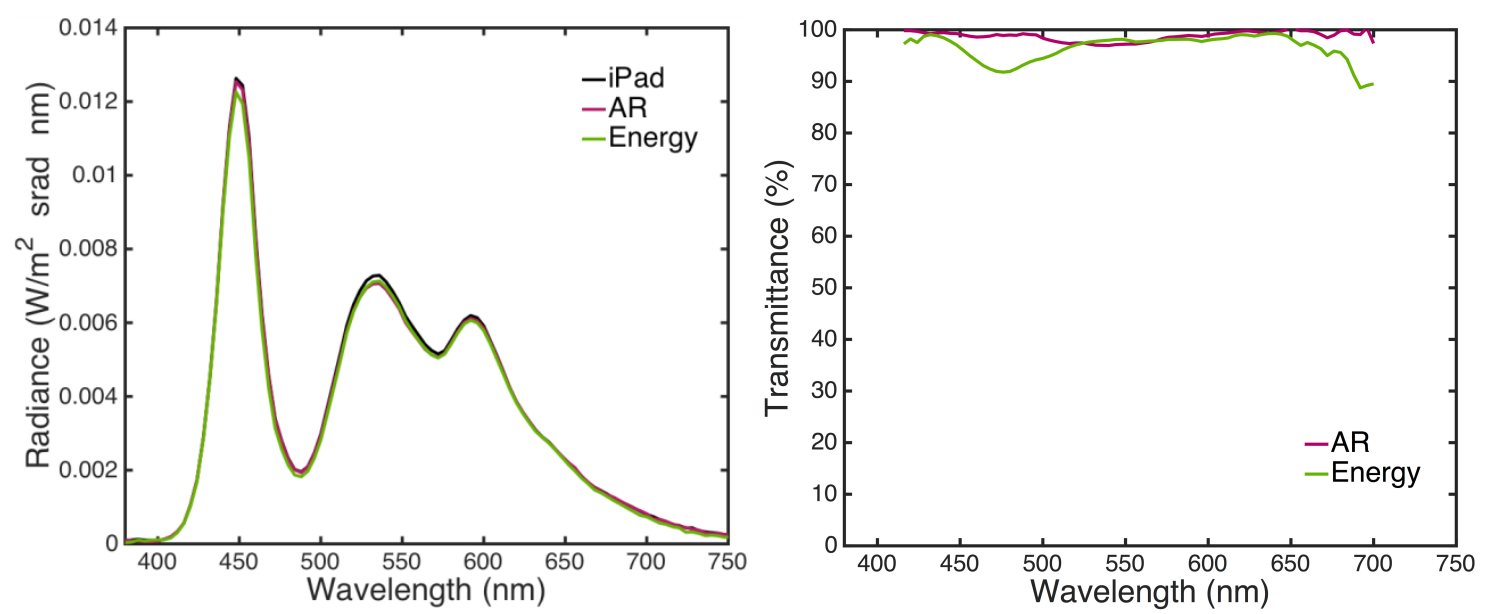

Fig. 6. Spectral radiances and transmittances obtained from the set of ophthalmic lenses from Indo. The curve of the tablet screen emission is shown for comparison.

The curves for the Blue Control sample of Hoya are plotted in Figure 7. This lens is directly compared with the emission of the tablet since the AR coating sample was not available in time for the study. It may be observed from Fig. 7 that the Hoya lens selectively absorbed only in the blue region of the visible spectrum, 
that is, it reduced slightly the maximum emission peak of the tablet in the short wavelength area. All the other wavelengths in the visible spectrum remained unaltered.
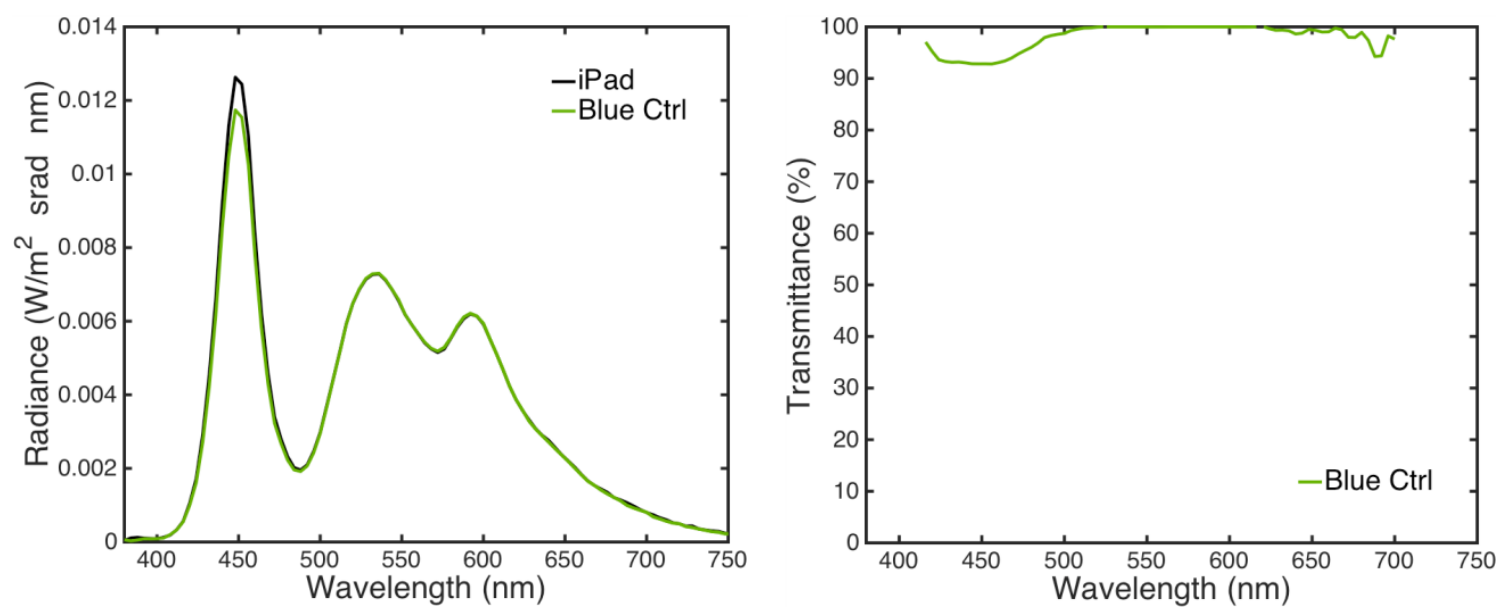

Fig. 7. Spectral radiances and transmittance obtained from the ophthalmic lens with Blue Control filter from Hoya. The curve of the tablet screen emission is shown for comparison.

Finally, the results from the Essilor samples are presented in Fig. 8. The radiance and transmittance curves evidence that the AR coating of Essilor did not affect the spectral information of the illuminating light source (tablet white screen). On the contrary, the Crizal Prevencia blue filter reduced a portion of the blue emission of the RGB LED screen. The other wavelengths of the visible spectrum remained unaltered with the incorporation of the blue filter.
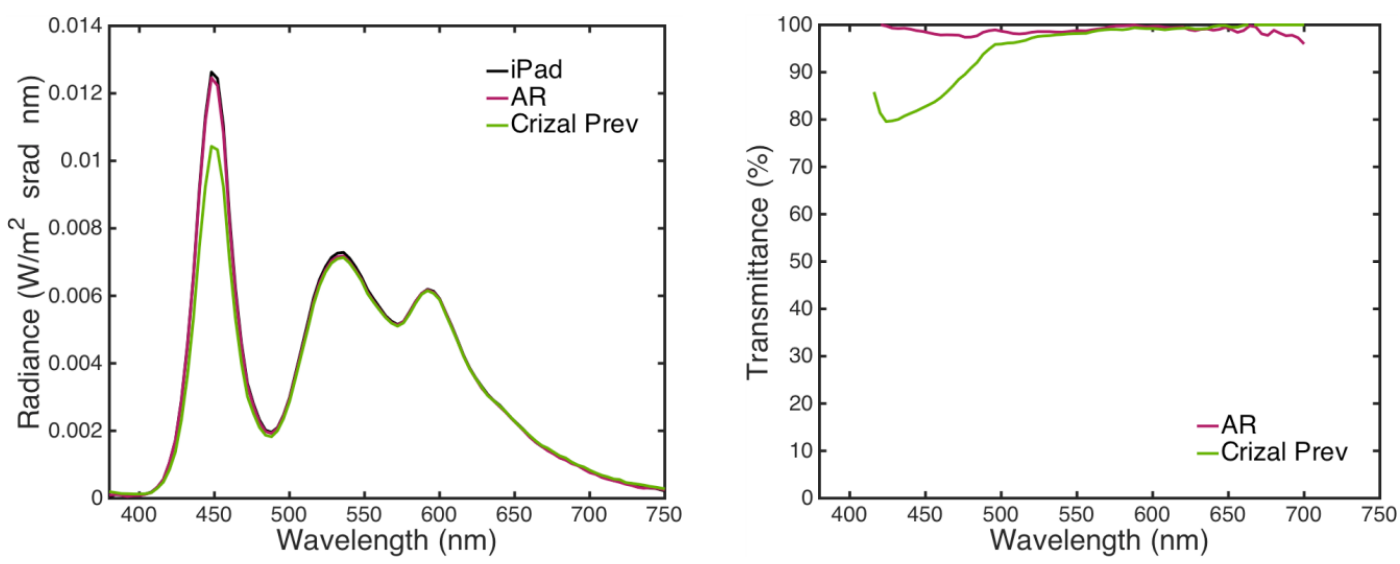

Fig. 8. Spectral radiances and transmittances obtained from the set of ophtthalmic lenses from Essilor. The curve of the tablet screen emission is shown for comparison.
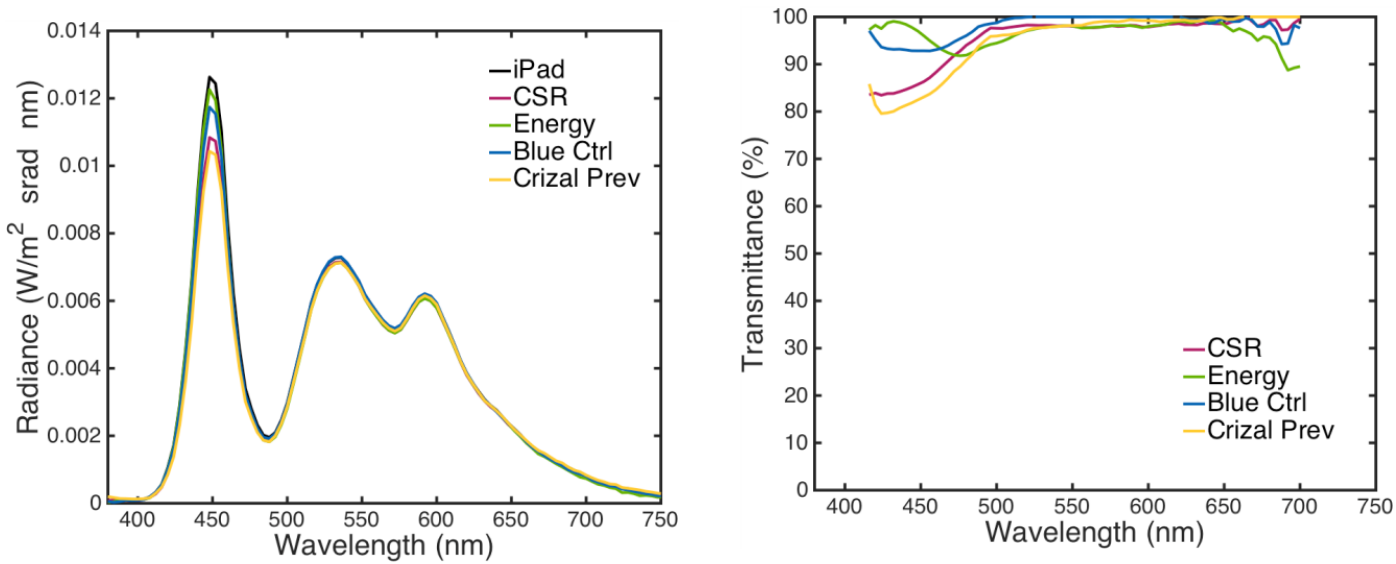

Fig. 9. Spectral radiances and transmittances obtained from the set of ophthalmic lenses incorporating blue filters. The curve of the tablet screen emission is shown for comparison. 
To allow for a better comparison between blue filters, Fig. 9 depicts the measured spectral radiance and transmittance of the tablet when the ophthalmic lenses incorporating blue filters for electronic device users are sequentially placed in front of the screen. It may be noticed that all tested lenses incorporating a blue filter performed a selective absorption in the blue region while transmitting the energy of the other wavelengths of the visible spectrum.

Table 2 summarizes the obtained experimental results in terms of the percentage of absorbed light at the maximum emission peak of the RGB LED self-luminous tablet for each ophthalmic lens with blue filter.

Table 2. Percentage of absorption at the maximum tablet emission peak for the tested ophthalmic lenses with blue filter.

\begin{tabular}{|c|c|}
\hline \hline Lenses & Absorption (\%) \\
\hline \hline Prats (CSR) & $14.7 \%$ \\
Indo (Energy) & $2.9 \%$ \\
Hoya (Blue Control) & $7.1 \%$ \\
Essilor (Crizal Prevencia) & $17.4 \%$ \\
\hline \hline
\end{tabular}

It may be noted from Table 2 that the percentage of blue light filter absorption varied significantly between manufacturers, with a range from 3\% of absorption for the Indo Energy sample to 17.4\% for the Essilor Crizal Prevencia lens. The Blue Control from Hoya and the CSR from Prats provided intermediate values of absorption, with a $7.1 \%$ and a $14.7 \%$, respectively. It is also interesting to remark that the degree of absorption of each lens coincided with the corresponding yellowish perception shown in Fig. 4. Thus, Figure 4(f) and 4(a) correspond to the highest blue light absorption of the Essilor and Prats samples, while Figure 4(e) and 4(d) are the mostly transparent lenses from Hoya and Indo.

\section{Conclusions}

In this study, the authors analysed several samples of ophthalmic lenses that incorporate blue light filters, specifically designed for electronic device users. As advertised by the manufacturers, these lenses are sold to prevent visual fatigue and ocular pathologies. To achieve this aim, the incorporated filters partially block the blue light emission of LED illuminating sources used in tablets and other electronic devices.

This study has firstly confirmed that a self-luminous iPad mini ME280TY/A (Apple tablet) presents an emission peak in the blue region of the visible spectrum, with a maximum radiance around $450 \mathrm{~nm}$.

Secondly, when placing AR coating ophthalmic lenses in front of the RGB LED illuminated tablet, the spectral radiance of the system remained unaltered for all the evaluated samples obtained from different manufacturers: Prats, Indo and Essilor.

Thirdly, ophthalmic lenses including blue filters for electronic device users were found to alter the spectral radiance of the tablet only in the blue region of the visible spectrum, specifically at its peak of maximum emission. Therefore, it may be concluded that commercially available blue filters in ophthalmic lenses are effective to absorb some of the short wavelength emission. Nevertheless, each commercial filter shows a different degree of blue light attenuation. The range of absorption among the four tested brands of lenses goes from $3 \%$ for the Indo sample to $17.4 \%$ for the Essilor sample. Additionally, it is relevant to note that lenses with the highest yellowish appearance correspond to those with the highest level of absorbance of the blue tablet emission.

The present findings revealing a wide range of blue light attenuation in commercially available blue filters support the need to accurately determine the blue light absorption level required to avoid possible ocular pathologies and fluctuations in the circadian rhythm.

\section{Acknowledgements}

Authors would like to thank the Ministerio de Economía y Competitividad (Spain) and FEDER funds for financial support (project DPI2013-43220-R). 